\title{
Replenishing a Balanced Mixture of Hormone Producing Cells: A Necessary Component in the Stem Cell Based Therapy for Diabetes?
}

\section{Jeroen Declercq* and John W. Creemers}

Laboratory for Biochemical Neuroendocrinology, Department of Human Genetics, University of Leuven, Belgium

Patients with type 1 diabetes produce little or no insulin due to an autoimmune destruction of the $\beta$-cell mass. Several decades ago, it has been demonstrated that diabetic rats could restore normoglycemia after transplantation with isogeneic islets [1]. This observation resulted in whole-pancreas or islet transplantation to treat patients with type 1 diabetes [2]. Nevertheless, several hurdles still need to be resolved before this strategy can be introduced for routine use. The major problem is the scarcity of transplantable islets. Therefore, several groups are currently trying to generate large numbers of $\beta$-cells in vitro from stem cells of both embryonic and adult origin for clinical utility [3]. Regarding this aspect, a lot of progress has been made and the company Viacyte optimized a reproducible method to generate implantable material from Cyt49 human embryonic stem cells, which is suitable for industrialization [4].

However, before going to therapy, several questions need to be resolved. Beside important safety issues (risk for the development of teratomas) and issues regarding the need of immunosuppressive drugs, it is also not clear how many $\beta$-cells ideally need to be transplanted and which cell type, derived from stem cells is the most suitable for transplantation. Although the answers to those questions remain elusive, we will discuss some aspects regarding those issues that will have to be taken into account.

It is well established that sufficient numbers of islets need to be engrafted to restore normoglycemia in diabetic recipients. However, due to a limited availability of islets for transplantation only few studies have addressed what would happen if too many cells are administered. It has been suggested that despite an increased $\beta$-cell mass, normoglycemia can still be achieved by a decrease in the insulin secretion on a per $\beta$-cell basis [5]. Alternatively, insulin secretion might remain elevated in normoglycemic animals due to decreased insulin sensitivity, as seen in some animal models with an increased $\beta$-cell mass [6]. To formally test what would happen if too many $\beta$-cells are engrafted, 1,000 syngeneic islets were engrafted under the kidney capsule of 10 to 12 week old $\mathrm{FVB}$ and $\mathrm{C} 57 \mathrm{Bl} / 6$ mice [7]. After an initial drop in the glycemia during the first 2-3 days, the transplanted mice restored normoglycemia, despite being hyperinsulinemic. Hyperinsulinemic euglycemic clamp experiments demonstrated that under those conditions normoglycemia is maintained by hepatic insulin resistance. Some degree of plasticity was also observed in the endogenous $\beta$-cell mass from the mice transplanted with excess $\beta$-cells. While the transplanted $\beta$-cell mass did not decrease for up to 2 months after transplantation, the endogenous $\beta$-cell mass was significantly decreased. Nevertheless, this decrease was not sufficient to prevent hyperinsulinemia in the transplanted animals. Transgenic mice over expressing the proto-oncogene Pleomorphic adenoma gene 1 (PLAG1) in the $\beta$-cells have an endogenous increase of the $\beta$-cell mass and show a similar phenotype as mice with an ectopic increase of the $\beta$-cell mass. They also remain normoglycemic despite being hyperinsulinemic due to hepatic insulin resistance [7]. Those experiments suggest that not only sufficient numbers of $\beta$-cells need to be transplanted but that transplantation of too many $\beta$-cells might lead to hepatic insulin resistance. Thus a proper dosage of the transplanted $\beta$-cell mass might be necessary when designing stem cell-based islet replacement therapies.
It is also not clear which cell type derived from hESC ideally need to be transplanted. The differentiation of hESC towards fully matured functional $\beta$-cells still remains very challenging. So far, nobody reported an in vitro differentiation protocol capable of generating sufficient amounts of exclusively insulin-producing cells meeting all essential criteria of functional $\beta$-cells as reviewed by Naujok et al. [8]. Nevertheless, it has been demonstrated that upon transplantation of pancreatic progenitors derived from hESC, the cells can mature further in vivo into glucose-responsive, insulin-secreting cells, restoring normoglycemia in diabetic animals. However, this in vivo maturation process takes several weeks. Refinement of current protocols to enable the generation of functionally competent $\beta$-cells entirely in vitro might be an alternative approach. Most likely, upon differentiation of stem cells into pancreatic $\beta$-cells, mixtures of $\beta$-, $\alpha$-, and $\delta$-cells will be generated and grafted. It might be important to take the balance of the different endocrine cells present in the transplant into account. Indeed, transgenic mouse models over expressing PLAG1 in different compartments of the pancreas differentially affect the hormone balance and have a different impact on the glucose homeostasis [9]. The Creinducible PLAG1 transgenic mouse model was intercrossed with $P d x 1$ Cre, Ngn3-Cre and Rip-Cre transgenic to target PLAG1 expression to different compartments of the pancreas (the whole pancreas, the endocrine cells and the $\beta$-cells, respectively). Those intercrossings resulted in P1-Pdx1Cre, P1-Ngn3Cre and P1-RIPCre mice, respectively. All mice developed islet hyperplasia, but with a different balance of the endocrine hormone-producing cells. In young P1-Pdx1Cre mice (less than 15 weeks), there was a balanced increase in the pancreatic content of insulin and somatostatin, which was associated with normoglycemia. In older P1-Pdx1Cre mice the pancreatic content of somatostatin far exceeded that of insulin, leading to severe hypoglycemia. In contrast in P1-Ngn3Cre mice and in P1-RIPCre mice, the pancreatic content of insulin exceeded that of somatostatin and those mice remained normoglycemic. The hypoglycemia in old P1-Pdx1Cre mice, but not in young P1-Pdx1Cre, P1-Ngn3-Cre and P1-RIPCre mice can possibly be explained that somatostatin can decrease insulin resistance [10]. By the huge increase in somatostatin which might prevent insulin resistance to occur. Indeed, it has been described alternatively, other hormones might contribute to the hypoglycemia in older P1-Pdx1Cre mice as well. Besides the PLAG1 transgenic mouse models, other mouse models such as those with mono- or biallelic loss of Arx and/or Pax4 also result in specific hormonal imbalances leading to normoglycemia,

*Corresponding author: Jeroen Declercq, Laboratory for Biochemical Neuroendocrinology, Department of Human Genetics, University of Leuven, Belgium Tel: 32-16-330128; Fax: 32-16-346073; E-mail: jeroen.declercq@med.kuleuven.be

Received July 26, 2012; Accepted July 28, 2012; Published July 30, 2012

Citation: Declercq J, Creemers JW (2012) Replenishing a Balanced Mixture of Hormone Producing Cells: ANecessary Component in the Stem Cell Based Therapy for Diabetes? J Steroids Horm Sci 3:e111. doi:10.4172/2157-7536.1000e111

Copyright: (c) 2012 Declercq J, et al. This is an open-access article distributed under the terms of the Creative Commons Attribution License, which permits unrestricted use, distribution, and reproduction in any medium, provided the original author and source are credited. 
Citation: Declercq J, Creemers JW (2012) Replenishing a Balanced Mixture of Hormone Producing Cells: A Necessary Component in the Stem Cell Based Therapy for Diabetes? J Steroids Horm Sci 3:e111. doi:10.4172/2157-7536.1000e111

hypoglycemia or even hyperglycemia depending on the levels of the different hormone-producing cells [11]. The data obtained from those different mouse models suggest that it is important to take the balance of the different endocrine cells into account to prevent hypoglycemia in diabetic patients treated by transplantation of stem cells differentiated to the pancreatic lineage.

In conclusion, the current advances in regenerative medicine provide hope for the development of a real cure for diabetic patients. It is clear that sufficient amounts of cells need to be transplanted to restore normoglycemia in diabetic patients, but on the other hand transplantation of too many cells might result in hepatic insulin resistance. Thus the number of transplanted cells should be appropriately determined. Furthermore, the right balance of different endocrine hormone-producing cells should be preserved in order to prevent hypoglycemia in the transplanted patients.

\section{References}

1. Ballinger WF, Lacy PE (1972) Transplantation of intact pancreatic islets in rats. Surgery 72 : $175-186$

2. Shapiro AM, Lakey JR, Ryan EA, Korbutt GS, Toth E, et al. (2000) Islet transplantation in seven patients with type 1 diabetes mellitus using a glucocorticoid-free immunosuppressive regimen. N Engl J Med 343: 230-238.

3. Kroon E, Martinson LA, Kadoya K, Bang AG, Kelly OG, et al. (2008) Pancreatic endoderm derived from human embryonic stem cells generates glucoseresponsive insulin-secreting cells in vivo. Nat Biotechnol 26: 443-452.
4. Schulz TC, Young HY, Agulnick AD, Babin MJ, Baetge EE, et al. (2012) A scalable system for production of functional pancreatic progenitors from human embryonic stem cells. PLoS One 7: e37004.

5. Zhang X, Gaspard JP, Mizukami Y, Li J, Graeme-Cook F, et al. (2005) Overexpression of cyclin D1 in pancreatic beta-cells in vivo results in islet hyperplasia without hypoglycemia. Diabetes 54: 712-719.

6. Bernal-Mizrachi E, Wen W, Stahlhut S, Welling CM, Permutt MA (2001) Isle beta cell expression of constitutively active Akt1/PKB alpha induces striking hypertrophy, hyperplasia, and hyperinsulinemia. J Clin Invest 108: 1631-1638.

7. Declercq J, Kumar A, Van Diepen JA, Vroegrijk IO, Gysemans C, et al. (2010) Increased beta-cell mass by islet transplantation and PLAG1 overexpression causes hyperinsulinemic normoglycemia and hepatic insulin resistance in mice. Diabetes 59: 1957-1965.

8. Naujok O, Burns C, Jones PM, Lenzen S (2011) Insulin-producing surrogate $\beta$-cells from embryonic stem cells: are we there yet? Mol Ther 19: 1759-1768.

9. Declercq J, Kumar A, Gysemans C, Di Pietro C, Schraenen A, et al. (2011) Pdx1- and Ngn3-Cre-mediated PLAG1 expression in the pancreas leads to endocrine hormone imbalances that affect glucose metabolism. Cell Transplant 20: $1285-1297$

10. Kollind M, Adamson U, Lins PE (1988) Somatostatin reduces posthypoglycemic insulin resistance in insulin-dependent diabetes mellitus. Acta Endocrino (Copenh) 118: 173-178.

11. Collombat P, Hecksher-Sørensen J, Broccoli V, Krull J, Ponte I, et al. (2005) The simultaneous loss of Arx and Pax4 genes promotes a somatostatin-producing cell fate specification at the expense of the alpha- and beta-cell lineages in the mouse endocrine pancreas. Development 132: 2969-2980. 